\title{
Anna Freud, una vida dedicada al conocimiento y a la ayuda psicológica del niño
}

\begin{abstract}
RESUMEN: Anna Freud fue una psicoanalista de la infancia que trató de dar continuidad a la obra de su padre. Revisamos en este trabajo su vida y sus trabajos más importantes, resaltando su aportación a la psicología del ego y las controversias que tuvo con Melanie Klein a partir de sus respectivas concepciones del desarrollo infantil y de los fenómenos transferenciales.
\end{abstract}

PALABRAS CLAVES: Anna Freud, Melanie Klein, psicoanálisis del niño, Controversias, psicología del ego.

\begin{abstract}
SUMMARY: Anna Freud was a child psychoanalyst that aimed to continue her father's work. We review on this paper some important aspects of her life and her most important works, outstanding her contributions to the Ego's psychology as well as the controversies with Melanie Klein on the differents approaches to the child development and transference phenomena.
\end{abstract}

KEY WORDS: Anna Freud, Melanie Klein, Child's psychoanalysis, Controversies, Ego'psychology.

La etapa vienesa de Anna Freud: años de formación y despegue

Anna Freud (1895-1982) vino al mundo en Viena el 3 de diciembre de 1895, siendo la sexta y última hija de Sigmund Freud y Martha Bernays. Annerl, como era conocida familiarmente, empezó su escolarización a los seis años, luego accedió al Lyceum y posteriormente se formó como institutriz de escuela primaria, llegando a dominar, además de su lengua materna, el inglés, el francés y algo el italiano. Durante la Primera Guerra mundial comenzó a frecuentar las reuniones de la Asociación Psicoanalítica de Viena y cuando dio fin la contienda bélica trabajó bajo la dirección de Siegfred Bernfeld en un orfelinato de niños judíos, el Instituto Baumgarten, que fue fundado en Viena en 1919 en el antiguo Hospital Militar (1). Pronto se integrará en esta institución Wilhelm Hoffer y los tres empezaron a reunirse periódicamente, grupo al que se sumaría August Aichhorn, que era director de una institución municipal para reeducar a jóvenes delincuentes, llamada Oberhollabrün, que había sido fundada en 1918.

En octubre de 1918, Anna empieza a psicoanalizarse con su padre, controvertido análisis que se extendió, en principio, hasta la primavera de 1920, tratamiento que dio comienzo tras haber abandonado su profesión de institutriz para recuperarse de una tuberculosis pulmonar. En la primavera de 1924, reemprendió su análisis durante un año más, ya que mostraba un inadecuado dominio de los fenómenos transferenciales en sus tratamientos (2). Antes de ello, en 1921, conoció a Lou Andreas-Salomé, iniciando un provechoso contacto personal y de formación. Lou, por ejemplo, le supervisó la

Rev. Asoc. Esp. Neuropsiq., 2002, vol XXII, n. ${ }^{\circ} 81$, pp. 65-78 
conferencia que pronunció el 31 de mayo de 1922 para ser admitida como miembro en la Asociación Psicoanalítica de Viena, titulada Las fantasías de flagelación y las ensoñaciones, que tenía un contenido autobiográfico oculto (2).

En torno a 1922 Anna asiste como invitada a la clínica universitaria del profesor Wagner-Jauregg, donde era el primer ayudante Paul Schilder y el segundo ayudante Heinz Hartmann (3). En 1923, pensaba instalarse en Berlín para continuar su formación y ejercer como analista, pero dio la cara el cáncer de paladar de su padre y se quedó para cuidarlo, misión que no abandonaría hasta su muerte. Por entonces, comienza su práctica psicoanalítica con pacientes adultos, pero muy pronto se ocupó del campo infantil, ya que por no ser médico sólo le estaba permitido trabajar con niños.

A finales de 1924, Anna había iniciado el tratamiento de una jovencita de 15 años llamada Minna, estableciendo paralelamente una sólida amistad con la madre de la chica, Eva Rosenfeld, con quien fundó una escuela infantil de orientación psicoanalítica, que era dirigida por Eva. Anna estaba por estos años muy interesada por la experiencia de Vera Schmidt en Moscú, donde había fundado un Laboratorio-Hogar para Niños en 1921 con el fin de tratar pedagógicamente a chicos pequeños bajo directrices psicoanalíticas (4). En el otoño de 1925 tomaría en tratamiento a Bob, uno de los hijos Dorothy Burlingham, que sería su gran amiga; poco después se ocuparía también de sus tres hermanos (Mabbie, Tinky y Mikey).
Cuando en 1925 se crea el Instituto Psicoanalítico de Viena, Anna es nombrada secretaria, siendo directora Helene Deutsch y director adjunto Siegfried Bernfeld. En el seno de este Instituto, junto a Hoffer, Aichhorn y Bernfeld, pone en marcha un seminario dedicado al psicoanálisis infantil (Kinderseminar).

Anna Freud, Dorothy Burlingham y Eva Rosenfeld, convencidas del valor del psicoanálisis cara a la educación del niño, crean en 1929 una escuela infantil en la casa de la última de ellas, donde trabajó Erik Erikson, que fue analizado por Anna. Por entonces, Anna Freud dictó una serie de conferencias para formar al personal que trabajaba en las guarderías de los barrios obreros de Viena y fue nombrada redactora del Zeitschrift für psychoanalytische Pädagogik, revista dirigida por Willie Hoffer, que desapareció en 1938 para ser reemplazada años después por The Psychoanalytic Study of the Child. En conexión con sus intereses de este período, Anna publica el libro Introducción al psicoanálisis para educadores (5), tratando de establecer pautas psicoanalíticas adecuadas con fines profilácticos para evitar futuros trastornos neuróticos en los niños. Con el paso del tiempo, cambiaría de opinión, percatándose de la necesidad de actuar no sólo educativamente, sino en forma terapéutica para poder llevar a cabo genuinas prevenciones (6).

En torno a 1935, Anna estaba preocupada por el desarrollo de los hijos de Dorothy, que ya eran adolescentes. La reflexión que derivó de estas observaciones fue la base de su texto más conocido y citado, editado el año siguiente, El yo y 
los mecanismos de defensa (7), en el que se da una gran importancia a la función adaptativa de algunas defensas del yo, sentando las bases de la psicología del ego.

En 1937, junto a Burlingham, y con el fin de ayudar psicoanalíticamente a los niños pobres y desamparados, Anna abrió en Viena la guardería Jackson, donde se ocupaba de los hijos menores de tres años de las obreras judías. Esta iniciativa se vio pronto frustrada, pues el 12 de marzo de 1938 los nazis clausuraron el centro y la Gestapo detuvo a Anna durante unas horas, episodio que convenció a Sigmund Freud de la necesidad de marcharse a Londres, cosa que hizo junto con parte de su familia el 4 de junio de 1938.

\section{Los iniciales enfrentamientos teóricos y técnicos con Melanie Klein}

Toda la experiencia que Anna había adquirido en su trabajo con chicos sirvió para la elaboración de otra obra fundamental, Psicoanálisis del niño (8), donde mostraba claras diferencias teórico-técnicas con el modelo que estaba proponiendo Melanie Klein a partir del Congreso Psicoanalítico de Salzburgo de 1924. Los enfrentamientos eran particularmente fuertes en lo que tocaba a los fenómenos transferenciales y al análisis precoz, negando Anna la existencia de una genuina neurosis de transferencia en los niños pequeños (por estar aún muy ligados a sus padres, lo que imposibilitaría el desplazamiento al analista de las actitudes y afectos que conforman la primitiva neurosis) y por tanto la posibilidad de un verdadero psicoanálisis en ellos, lo que obligaba al terapeuta a comprometerse con el fortalecimiento del inmaduro yo infantil, así como ayudar al establecimiento de un superyó armónico a través de acciones educativas o de apoyo. Además, no aceptaba el juego como equivalente de la asociación libre, calificando de salvajes las interpretaciones de Klein, criticando su excesivo interés por la realidad psíquica subjetiva con abandono de la realidad objetiva. Klein (9) defendía la presencia de particulares angustias y defensas desde momentos muy precoces del desarrollo, las cuales invadirían las fantasías de los juegos infantiles en el encuadre psicoanalítico por ella definido, manteniendo con tenacidad su convicción de la realidad de los fenómenos transferenciales de sus pequeñísimos pacientes y resaltando la necesidad de interpretarlos analíticamente para lograr la cura, excluyendo todo matiz pedagógico.

\section{La etapa británica: las "Grandes Controversias"}

Tras la muerte de Sigmund Freud en Londres, el 23 de septiembre de 1939, Anna se dispuso a continuar su trabajo psicoanalítico, aunque la Segunda Guerra mundial vino a complicar las cosas. Por entonces, los kleinianos eran dueños de la Asociación Psicoanalítica Británica y vivieron mal la presencia de Anna, pues pensaban que podía alterar la autonomía alcanzada respecto a los psicoanalistas centroeuropeos. Estos enfrentamientos abocarían en las llamadas Grandes Controversias que se extendieron desde 1941 a 1945, que llevaron a confrontaciones muy intensas entre los annafreudianos y los kleinianos. 
Por otro lado, en 1941, Anna y su grupo crean una guardería y residencia en el n1 13 de la calle Wedderburn, zona de Hampstead, destinadas a los niños del East End que habían vividos terribles experiencias de bombardeos en la guerra y que se encontraban en una indigencia absoluta. Así mismo puso en marcha un centro de evacuación cerca de Essex para chicos mayorcitos, en una casa de campo llamada New Barn, además de una institución para bebés en el n1 5 de Netherhall Gardens, llegando a atender allí a más de ciento veinte niños. Estas experiencias llevaroron a Anna Freud y Dorothy Burlingham, que vivían juntas en Maresfield Gardens 20, a percatarse que las reacciones psicopatológicas de los niños a los bombardeos estaban determinadas sobre todo por las formas en que actuaban sus madres ante tales eventos, así como por la acción traumática dada por la separación de los padres, sobre todo si era brusca o brutal y si existían sentimientos edípicos ambivalentes. Algunas de estas ideas, así como la importancia que tenía para los niños criarse en un entorno familiar y no en instituciones (tesis que Aichhorn había defendido con ahínco) fueron recogidas en dos trabajos, junto a Burlingham, titulados La guerra y los niños (10) y Niños sin familia (11), donde se subraya que las primeras relaciones niño-madre determinaban todas las ulteriores. Años después Anna profundizará en este tema en el artículo titulado Madre rechazante (12), producto de una conferencia que había pronunciado en Estados Unidos.

En la guardería de Hampstead se preparaba al personal en temas muy variados acerca de la infancia (salud física y mental, desarrollo emocional y cognoscitivo, educación según el modelo Montessori, tareas de gestión, etc.), organizándose pequeñas familias con cuatro o cinco chicos y una mamá (pues no había suficiente personal masculino para proporcionar padres sustitutos), mostrando tal modelo unos excelentes y rápidos resultados terapéuticos. La residencia se cerró en febrero de 1942, por falta de medios económicos, dedicándose el edificio sólo a guardería, que también hubo de clausurarse al finalizar la guerra. Por ello, Anna y Dorothy crearon y desarrollaron a partir de 1947, con fondos aportados desde los Estados Unidos, la Clínica Hampstead (que hoy se llama Centro Anna Freud), con el fin de formar a un amplio personal en el campo psicoanalítico y atender terapéuticamente a los niños y a sus familias.

Por estos años se inician las antes citadas Grandes Controversias en el seno de la Asociación Británica de Psicoanálisis, que colocaron a los annafreudianos y los kleinianos ante una confrontación aparentemente científica, pero tras la que latía una lucha por el control y el poder (13). De entre los datos más significativos de los conflictos habidos, destacamos que en una reunión del 29 de julio de 1942 se tomó la decisión de propiciar un encuentro mensual para discutir las diferencias científicas entre las dos tendencias psicoanalíticas citadas, cuyo programa de trabajo habría de correr a cargo de Edward Glover, Marjorie Brierley y James Strachey. Tras ello, la reunión del 21 de octubre de 1942 marcó el auténtico comienzo de los enfrentamientos, planteando Anna Freud que las dos teorías que se ponían a 
discusión, la freudiana y la kleiniana, no podían coexistir, especialmente en lo que tocaba al narcisismo primario, las relaciones precoces con el objeto, la introyección, la proyección, el papel de la pulsión de muerte, la llamada posición depresiva y la existencia de conflictivas neuróticas en los niños desde los seis meses de edad.

Las diversas comunicaciones de algunas de las discípulas de Klein, que se fueron presentando en sucesivas reuniones, trataban de demostrar que la aportación de ésta no era sino un desarrollo del freudismo. De entre los trabajos discutidos, fue fundamental el presentado por Isaacs, titulado $L a$ naturaleza y función de la fantasía (14), que dio lugar a interesantísimas aportaciones ulteriores. En la sesión del 7 de abril, Anna Freud expresó su posición, insistiendo en no aceptar la existencia de relaciones objetales precoces, que para ella aparecerían tras una fase narcisista y autoerótica, donde el niño sólo se preocupaba de su bienestar, sin amar, odiar, desear, atacar o desmembrar a la madre, la cual sólo sería importante en la medida en que sirve a su bienestar o lo perturba. El 9 de mayo, tras la discusión del citado trabajo de Susan Isaacs, que resaltaba la existencia de una fantasía precoz cargada de elementos libidinales y tanáticos en las relaciones objetales, Paula Heimann (15) presentó una comunicación en torno a las funciones de la introyección y la proyección en la primera infancia, ocupándose de la descripción del yo primitivo y de las relaciones objetales precoces, estableciendo una distinción entre la identificación introyectiva y la introyección, lo que conducía al esclarecimiento de matices importantes en la formación del yo y del superyó, estableciendo novedosas líneas de explicación del desarrollo humano.

Tras interminables y duros debates, votaciones más o menos manipuladas y críticas personales feroces, así como algunas inesperadas dimisiones como la de Edward Glover (que estaba aliado con Melitta Schmideberg, hija de Melanie Klein y enfrentada a ésta), los conflictos se calmaron en mayo de 1944 y dieron fin en noviembre de 1946 con la firma de un documento que aceptaba dos tipos de formación psicoanalítica, la constituida por el denominado curso $A$, que acogería a los kleinianos y a los independientes (middle group), y el llamado curso $B$, que agruparía a los annafreudianos, estando ambos cursos bajo la supervisión de un único Comité de Formación, responsable de la selección, formación y calificación de los candidatos. Habría, además, seminarios y conferencias comunes al margen de los dedicados a la técnica, a los que debían asistir todos los estudiantes, pudiendo acudir como invitados a los de técnica que no fueran de su afiliación teórica, aunque a partir del tercer año de formación todos debían estar presentes en el conjunto de las actividades dedicadas a la técnica (13). Todo ello supuso un beneficio para Klein, pues pudo organizar desde entonces una escuela en cierta forma autónoma (16). Con el paso de los años, y sobre todo tras la muerte de Melanie Klein en 1961, los referidos acuerdos fueron modificándose, atenuándose más y más las diferencias entre ambos grupos, hasta que llegó a aplicarse una formación común para todos los alumnos a partir de 1967 (13). 
El enfrentamiento entre Anna Freud y Melanie Klein puede entenderse si se ahonda en las ideas centrales de una y otra: téngase en cuenta que aquélla partía de una concepción de la transferencia según el modelo que había establecido su padre, esto es, una reedición en el encuentro analítico de las conflictivas pulsionales que habían quedado enquistadas en el aparato psíquico desde un momento relativamente tardío de la infancia (neurosis primitiva), mientras que para Klein el niño ponía en marcha desde el mismo nacimiento su preponderante fantasía inconsciente (representación psíquica de lo pulsional), cargada de conflictos, lo que ocurriría tanto en la relación con los objetos internos, como con los padres o cualquier otro objeto externo, como sería el caso del analista cuando el niño es tratado. La transferencia no sería, pues, la reedición de una neurosis anterior, sino la aparición de una conflictiva permanente (posiciones no bien superadas, particularmente la posición depresiva) que se vive en el momento actual y que puede invadir cualquier relación presente, como es el caso de la situación analítica. De aquí que Klein hablara de situación transferencial y no de neurosis transferencial (17). Por otro lado, dado que Klein mantenía la presencia en el niño pequeño de un superyó precoz muy sádico y cruel, toda actuación sobre éste, en el sentido pedagógico preconizado por Anna Freud, sólo abocaría en un empeoramiento del estado del conflicto inconsciente del niño en tratamiento, puesto que fortalecería la rigidez y los excesivos controles de tal instancia psíquica. Melanie insistía, pues, en un análisis en toda regla desde los tres años aproximadamente, con interpretaciones de la transferencia en el marco de las primitivas ansiedades y defensas, aunque, en un momento dado, Klein (18) señaló que debían analizarse las fantasías inconscientes que el paciente pone en marcha en su vida actual más allá del aquí y ahora de la sesión, lo que superaba las posturas que había sostenido con anterioridad.

\section{Pionera de la psicología del ego}

Aunque fueron sin duda Alfred Adler y Wilhelm Reich quienes pusieron las bases para la psicología del ego, tales aportaciones no se aceptaron en el seno del psicoanálisis hasta que Anna Freud dio al yo un lugar fundamental en la formación y disolución de las neurosis, en el sentido de señalar el papel adaptativo de las defensas, lo que recogió en El yo y los mecanismos de defensa (10), que estaba inserto en la perspectiva estructuralista de la segunda tópica freudiana y en las principales ideas de Reich (19), aunque matizando que el análisis de las defensas no tenía porque ser algo sistemático, sino que tal trabajo debía oscilar entre el yo y el ello en función del estado metapsicológico en que se encontrase el conflicto activado. En tal línea, Anna subrayó que algunas de las defensas del niño no se organizan contra las pulsiones procedentes del ello, sino como formas más o menos adaptativas del yo ante las presiones de los padres o del entorno. Por otro lado, aportó interesantes novedades en torno a la psicología de la adolescencia, esclareciendo peculiares procesos defensivos tales como la intelectualización y el ascetismo, que explicaban variadas y contradictorias conductas y rasgos caracteriales de los jóvenes, antes escasamente comprendidos. 
Al citado libro de Anna Freud siguió la famosa monografía de Hartmann La psicología del ego y el problema de la adaptación (20), donde se distinguieron dos componentes en el yo (ego), uno que tendría que ver con los conflictos y otro fruto de la maduración, el cual en principio estaría libre de ellos. Además, se referían dos clases de conflictivas intrapsíquicas, las intersistémicas (entre el yo y el ello/superyó) y las intrasistémicas (entre distintas partes del ego, especialmente entre el área conflictiva y el área libre de conflictos), todo lo cual permitió la organización de interesantes matices técnicos con una adecuada fundamentación teórica. En esta misma línea, tres artículos simultáneos sobre la interpretación, uno de Rudolph Löwenstein (21), otro de Ernest Kris (22) y un tercero del propio Heinz Hartmann (23) representaron la aplicación técnica de las innovaciones teóricas. Más tarde, en Ensayos sobre la psicología del ego (24), Hartmann matizó que el elemento primordial de la cura radicaba en la neutralización de las energías sexuales y agresivas por medio de la interpretación, pues de tal cosa depende la instauración del principio de realidad y la adecuada adaptación.

Las aportaciones de la psicología del ego no fueron bien vistas por algunos psicoanalistas, como por ejemplo Jacques Lacan, que lanzó virulentos ataques contra sus defensores, acusándolos de abandonar a Freud, adoctrinar a sus pacientes y normativizarlos en función de la cultura norteamericana (25), críticas que no son, a nuestro entender muy acertadas, pues la psicología del ego tuvo el mérito de haber hecho un acercamiento a la psicología cognoscitiva, llamando la atención acerca de ciertas variables que funcionan con cierta independencia de las motivaciones y conflictos inconscientes, abriendo las puertas a lo que Bieber ha llamado psicoanálisis cognoscitivo (26).

Compromiso total con la educación y la terapia psicoanalíticas del niño y de su familia

Como hemos referido, tras la finalización de la segunda gran contienda mundial, se cerraron los centros para la infancia que Anna y Dorothy habían creado en Londres, empezando ambas a participar en un proyecto de investigación sobre las consecuencias de la guerra para los niños, lo que acabó de convencerlas del papel definitivo que tenía la madre y los adultos en general en el desarrollo infantil. Ello hizo que a partir del otoño de 1945, Anna se ocupase de la dirección de un hogar llamado Bulldogs Bank, en Sussex, donde se instalaron seis niños judíos que habían perdido a sus padres poco después de nacer y que habían estado con posterioridad en campos de concentración o instituciones similares. Estos niños formaban un grupo enormemente cohesionado, mostrando mucha agresividad hacia los demás, manteniendo una actividad masturbatoria permanente y compulsiva y un estado de retraso madurativo. La observación y estudio de estos chicos mostró la importancia de las relaciones con los adultos y lo patologizante que suponía su pérdida, todo lo que sirvió para la posterior elaboración de un trabajo de mucho interés junto a Sophie Dann (27).

Años antes, Anna había recibido la noticia de la muerte, que habían 
acontecido en 1942, en campos de concentración nazis, de sus cuatro tías paternas. En un estado de confusión y tristeza, trató de compensarse de la forma que en ella era habitual, trabajando incansablemente por y para el psicoanálisis, redactando además varios trabajos acerca de las necesidades de la educación temprana (28), de los trastornos alimentarios de los jóvenes $(29,30)$ y del dormir en la infancia (31). Por entonces, Anna también fue tomando notas para lo que sería el ensayo titulado La pérdida de objetos. Perder y perderse (32), donde pueden observarse influencias de Winnicott, particularmente las referidas a la importancia de los objetos transicionales, matizando lo que ocurre con estos objetos cuando sucede una pérdida definitiva de la madre: los objetos transicionales son sobrevalorados y paralelamente rechazados, lo que expresa los sentimientos ambivalentes que subyacen respecto del primitivo objeto perdido.

En otro orden de cosas, Anna, dados los enfrentamientos entre sus propuestas técnicas y las de Klein, redactó Indicaciones para el análisis (33). Bastantes años después hablaría acerca de las contraindicaciones del análisis en la infancia en la Tercera Asamblea Científica Anual celebrada en New Haven (Connecticut) en la Asociación Norteamericana de Psicoanálisis Infantil (34). Durante la década de los cuarenta Anna también se ocupó de investigar acerca de los aspectos intersubjetivos de la adolescencia, ahondando en la serie de conductas defensivas propias de esta etapa del desarrollo, tratando de dar cuenta psicoanalítica de las fantasías que crean las novelas familiares, así como de las conductas antisociales y suicidas y de ciertos trastornos alimentarios de esta etapa del desarrollo.

Otra de las consecuencias de la serie de experiencias de la posguerra fue la puesta en marcha de un programa de acogida por familias de los niños afectos de pérdida de los padres, como una mejor alternativa a su ingreso en orfelinatos. Así mismo Anna alertó acerca de las consecuencias negativas de las hospitalizaciones prolongadas de los niños, dado que conllevaban bruscas rupturas de las relaciones con su madre y con su hogar, tarea en la que fue ayudada por John Bowlby y el trabajador social James Robertson, que insistían en la conveniencia de la permanencia de la madre junto al hijo en el hospital para prevenir efectos indeseables en el desarrollo psíquico (2).

Como antes hemos referido de pasada, en lo que toca al compromiso por ayudar a la infancia trastornada y a sus familias, Anna fundó en 1947 la Clínica de Terapia Infantil Hampstead, en Maresfields Gardens 21, local situado junto a su casa, que sustituía a las antiguas guarderías de la guerra. Aquí comenzó ofertando un curso de entrenamiento en psicoanálisis infantil, abriéndose los diversos servicios de la clínica en 1952, momento a partir del cual evolucionó hasta convertirse en un centro de formación, de terapia y de investigación en el campo del psicoanálisis de niños desde los dos años de edad que estuvieran afectos de variados problemas neuróticos, de trastornos límites y de psicosis, así como casos especiales de niños discapacitados, como ciegos (35). El trabajo de investigación se apoyaba en 
observaciones cuidadosamente registradas y datos provenientes de otras fuentes, con cuya base se construyó un instrumento clínico denominado Índex o Perfil diagnóstico Hampstead, un sistema ideado por Burlingham para evaluar los aspectos multifacéticos del desarrollo del niño (36) y que fue desarrollándose a partir de los años sesenta bajo la dirección de Joseph Sandler (37). Las principales ideas al respecto aparecieron en el texto de Anna intitulado Normalidad y patología en la niñez (6), particularmente las diferentes líneas de desarrollo normales y el perfil metapsicológico correspondiente.

Las cosas transcurrieron relativamente serenas hasta 1949 , pues el 17 de octubre de ese año falleció su gran amigo y permanente enamorado August Aichhorn, un especialista en el abordaje psicoanalítico de la delincuencia juvenil. Superadas ésta y otras pérdidas afectivas, Anna siguió con su trabajo clínico y científico, viajando a Norteamérica para dar una serie de conferencias en 1949, conjunto que le sirvió para elaborar la antes citada monografía Normalidad y patología en la niñez, donde separa con claridad la psico(pato)logía del niño de la del adulto (6).

Hacia abril de 1950, Anna participó en un simpósium celebrado en Stockbridge (Massachusetts) donde habló de las características del desarrollo del niño a partir de las observaciones psicoanalíticas (38). Ese mismo mes tuvo lugar un evento de interés histórico: Anna fue invitada a asistir a la Clark University para festejar el sesenta aniversario de esta institución, donde habló de La contribución del psicoanálisis a la psicología genética (39), revisando concienzudamente las aportaciones de la psicología académica, lo que sin duda la fue muy útil cuando puso en marcha su proyecto de investigación en la Clínica Hampstead. Dio así mismo otras conferencias en Nueva York sobre homosexualidad masculina y en el Riggs Center de Stockbridge sobre observaciones del desarrollo del niño (2).

En 1951, en el XVII Congreso Internacional de Psicoanálisis celebrado en Amsterdam (Holanda), Anna presentó una novedosa aportación en torno a la homosexualidad masculina, fruto del análisis de cuatro casos de años anteriores. Mostró la posibilidad de modificar la potencia fálica y dirigirla heterosexualmente, aunque admitió que sus pacientes continuaban emocionalmente impotentes, reflexionando que tales sujetos viven la relación con un objeto de amor en forma exclusivamente pasiva, sirviendo la impotencia como medio para preservar la amenaza de ser maltratado o abandonado: rechazar los objetos heterosexuales de amor, dijo en términos de la psicología del ego, supone preservar la integridad del yo (2).

En 1952 pudo ponerse completamente en marcha la Clínica Hampstead para ocuparse de los niños psíquicamente trastornados y de sus madres, gracias al apoyo económico del filántropo norteamericano Marshall Field, en lo que le fue muy valiosa la ayuda de Helen Ross, que llevaba a cabo un programa de terapia infantil en el Instituto Psicoanalítico de Chicago (2). El centro, situado en Maresfield 21 de Londres, contaba con seis consultorios, un salón de juegos, una pequeña biblioteca y un aula para conferencias. Su éxito fue notable, como 
lo indica que en 1955 se analizaban sesenta niños y por la serie de ampliaciones en la oferta clínica (niños minusválidos y bebés sanos, trabajo con padres, etc.), además de ponerse en marcha en 1956 un centro para preescolares en Maresfield Gardens 12, esta vez con la ayuda de la Fundación New-Land, patrocinada por Muriel Gardiner. Por entonces se elaboró el antes referido Índex o Perfil diagnóstico, donde el criterio clasificador no era el dado por las tradicionales categorías psiquiátricas del adulto, sino basándose en aspectos madurativos y otras influencias, lo que sus detractores calificaron como un potpurrí (40).

Por otro lado, durante la década de los cincuenta, Anna elaboró una serie de trabajos interesantes en relación con aspectos psíquicos de las enfermedades físicas, intervenciones quirúrgicas, ingresos hospitalarios, etc. de los niños: así, en Enfermedad somática y vida psíquica (41) Anna aportó nuevas ideas sobre la aparición de estados neuróticos en los chicos que aquejaban distintas enfermedades orgánicas o se habían sometido a intervenciones quirúrgicas, pues de hecho una y otra cosa suele suponer una separación de la madre y la inclusión de diversas restricciones en la vida normal; en La visita al niño hospitalizado (42) Anna se ocupó de la necesidad de evitar la ruptura de los contactos niño-madre en las hospitalizaciones, subrayando en todos estos trabajos la necesidad que tenía el personal médico de ocuparse no sólo de las consecuencias de las enfermedades o las intervenciones quirúrgicas sobre la corporalidad, sino también de sus efectos en el psiquismo infantil.
El año 1956 era el del centenario de la muerte de su padre y Anna deseaba celebrarlo publicando un libro, como había hecho veinte años antes, disponiéndose también a dar unidad a una serie de conferencias que había dictado, lo que fue el cuerpo de un texto de años posteriores, Normalidad y patología en la niñez (6). En septiembre fue invitada a dictar una conferencia en la Western Reserve University de Cleveland, donde disertó acerca de la tarea psicoanalítica en la crianza del niño, en la línea que siempre venía manteniendo: la importancia del cuidado real de los que rodean al niño para que se establezca un desarrollo correcto (43).

En 1957, Anna Freud asistió al XX Congreso Internacional de Psicoanálisis celebrado en París, donde leyó dos interesantes comunicaciones sobre el valor para el psicoanálisis de la observación directa del niño (44) y una breve historia de la evolución del psicoanálisis infantil (45), que ampliaría años después en una conferencia que dio en Topeka (Kansas) el 9 de abril de 1966 con motivo del Primer Encuentro Científico de la Asociación Norteamericana de Psicoanálisis de Niños (46). El año 1957 también fue un año triste, pues falleció Ernst Kris, a los cincuenta años de edad. En una reunión homenaje al fallecido, celebrada en la Sociedad e Instituto Psicoanalítico de Nueva York, Anna presentó un trabajo en el que aportaba ideas sobre el método de observación y los hallazgos del citado Kris ante el diagnóstico y pronóstico de los trastornos del desarrollo en la infancia (47). Poco después participó en el XXXV Aniversario del Centro de Orientación Juvenil de Worcester (Massachusetts), hablando de la 
terminación del análisis (48). Así mismo, colaboró en un simpósium en torno a la orientación y el análisis infantil, en el que se refirió a las características que deben guiar a una clínica psicoanalítica con el fin de prevenir y esclarecer las conflictivas del desarrollo (49). En esta misma reunión habló de la adolescencia, enriqueciendo la serie de procesos defensivos que ya había establecido con modalidades específicas dirigidas contra los vínculos objetales preedípicos y edípicos (50). Por otro lado, en una conferencia que pronunció en mayo de 1959 en el Grupo de Estudios de la Sociedad de Investigación Psicosomática del Real Colegio de Médicos de Londres, volvió a hablarle a los pediatras acerca de la necesidad de considerar en el niño enfermo algo más que el cuerpo (51).

La década de los sesenta fue de gran productividad intelectual, destacando la aportación, en abril de 1964, a un simpósium celebrado en Nueva York, donde planteó interesantes consideraciones metapsicológicas, madurativas y diagnósticas en el trauma infantil (52). Un año después, en el libro de Bergmann titulado Niños en el hospital, Anna redactaría un capítulo sobre las consecuencias psicológicas de las hospitalizaciones prolongadas, tratando una vez más de aportar su granito de arena para disminuir el sufrimiento infantil (53). En abril de 1966 disertó brillantemente en la Universidad de Yale acerca de los cuidados que necesitan los niños que han de criarse en hogares sustitutos o en instituciones diversas (54). Y en la primera reunión de la Asociación Americana para el Psicoanálisis de los Niños, celebrada en Topeka (Kansas), habló de la historia del análisis infantil, mostrando la necesidad de constituir una formación específica en tal campo (46). En el Colegio Médico Jefferson, como agradecimiento por habérsele otorgado un doctorado honoris causa, se refirió al currículum adecuado que ha de poseer un analista profano, comentando su propia formación (3). En 1969 aparecen otros dos artículos intitulados Dificultades en el camino del psicoanálisis (55) y Los conocimientos psicoanalíticos aplicados a la educación infantil (56) y un año después, el 18 de abril de 1970, dio una conferencia en la Sociedad Psicoanalítica de New Haven (Connecticut) en torno a la aplicación del perfil diagnóstico (Índex) que se usaba en Hamsptead a la hora de afrontar la sintomatología infantil, abordando el estado del desarrollo en el marco de un panorama global de la personalidad (57).

Debe destacarse también que a mediados de los sesenta, por intermedio de Jeanne Lampl de Grot, la Asociación Psicoanalítica Holandesa trató de propiciar un programa de capacitación en análisis infantil reconocido por la API, según el programa que Anna Freud había desarrollado con el personal de Hampstead. No pudo conseguirse, pues la mayoría de los miembros de la API se mostraban reacios a crear una doble formación (adultos y niños), pues temían que ello abocara en futuras escisiones.

En el Congreso Psicoanalítico que se celebró en Jerusalén en 1977, año en que se inauguró la primera cátedra de psicoanálisis en la Universidad Hebrea, Anna se preocupó porque la persona elegida para desempeñar tal cátedra no fuera un oportunista deseoso de hacer propaganda de las últimas teorías con pretensiones renovadoras, pero que en 
el fondo iban degradando la esencia del genuino psicoanálisis. Por eso tomó con ilusión la publicación de las obras selectas de su padre (58), para la que redactó una introducción titulada Guía para el estudio de los trabajos de Freud (59).

A comienzos de 1978, Anna tenía una salud física y psíquica francamente malas. Había dejado la dirección de la Clínica Hampstead a Clifford Yorke y a Hansi Kennedy. Su situación se agravó el 19 de noviembre de 1979 con la muerte de Dorothy Burlingham. El 1 de marzo de 1982, Anna Freud sufría un accidente cerebro-vascular, quedando con un trastorno afásico-apráxico y teniendo que ser desplazada en una silla de ruedas cubierta con el abrigo de su padre. En la madrugada del día 9 de octubre de 1982 falleció, dejando su legado en los ocho volúmenes de The Writings of Anna Freud, 1966-1980 (60), donde quedaron recogidas todas sus ideas y sus inalienables compromisos con el psicoanálisis infantil.

\section{BIBLIOGRAFÍA}

(1) Bernfeld, S. "La colonia infantil de Baumgarten". En El psicoanálisis y la educación antiautoritaria. Barcelona: Barral Editores, 1973, pp. 99-210.

(2) Young-Bruehl, E. Anna Freud. Buenos Aires: Emecé Editores, 1991.

(3) Freud, A. Currículum vitae de un psicoanalista profano". En Pasado y presente del psicoanálisis. México: Siglo XXI, 1972, pp. 83-95.

(4) Geissmann, C. y Geissmann, P. Histoire de la psychanalyse de l'enfant. Paris: Bayard. 1992

(5) Freud, A. Introducción al psicoanálisis para educadores. Buenos Aires: Paidós, 1948.

(6) Freud, A. Normalidad y patología en la niñez. Buenos Aires: Paidós, 1974.

(7) Freud, A. El yo y los mecanismos de defensa. Buenos Aires: Paidós, 1965.

(8) Freud, A Psicoanálisis del niño. Buenos Aires: Hormé, 1980.

(9) Klein, M. Simpósium sobre análisis infantil. En Obras Completas, 1. Barcelona: Paidós, 1989, 148-177.

(10) Freud, A. y Burlingham, D. T. La guerra y los niños. Buenos Aires: Hormé, 1965.

(11) Freud, A. y Burlingham, D. T. Infants without Families. New York: International Universities Press. 1944

(12) Freud, A. "La madre rechazante". En Psicoanálisis del jardín de infantes y la educación del niño. Barcelona: Paidós, 1992, 17-28.

(13) King, P. y Steiner, R. Les Controverses Anna Freud-Melanie Klein, 1941-1945. Paris: PUF, 1996.

(14) Isaacs, S. "La naturaleza y función de la fantasía". En M. Klein y otros, Desarrollos en psicoanálisis. Buenos Aires: Hormé, 1967.

(15) Heimann, P. "Ciertas funciones de la introyección y la proyección en la primera infancia". En M. Klein, P. Heimann, S. Isaacs y J. Riviere, Desarrollos en psicoanálisis. Buenos Aires: Hormé, 1967.

(16) Grosskurth P. Melanie Klein. Su mundo y su obra. Barcelona: Paidós, 1990.

(17) Petot, J. M. Melanie Klein. Primeros descubrimientos y primer sistema (1919-1932). Buenos Aires: Paidós, 1982. 
HISTORIA

(18) Klein, M. "Los orígenes de la transferencia". En Obras Completas, 3. Barcelona: Paidós, 1988, 57-65.

(19) Reich, W. Análisis del carácter. Buenos Aires: Paidós, 1977.

(20) Hartmann, H. La psicología del yo y el problema de la adaptación. México: Pax-México, 1962.

(21) Löwenstein, R. M. "The Problem of Interpretation". Psychoanalytic Quarterly, 20, 1-14. 1951

(22) Kris, E. Ego Psychology and Interpretation in Psychoanalytic Therapy. Psychoanalytic Quarterly, 1951. 20, 15-30.

(23) Hartmann, H. "Technical Implications of Ego Psychology". Psychoanalytic Quarterly, $195120,31-43$.

(24) Hartmann, H. Ensayos sobre la psicología del yo. México: Fondo de Cultura Económica, 1969.

(25) Bleichmar, N. y Leiberman, C. El psicoanálisis después de Freud. Teoría y técnica. México: Eleia, 1989

(26) Poch, J. y Talarn, A. "Aproximación entre la psicología dinámica y la cognoscitiva: aspectos teóricos". En J. Poch y otros, Aproximaciones conceptuales en psicología y psicoterapia. Barcelona: Hogar del Libro, 1991.

(27) Freud, A. y Dann, S. "La crianza en grupo. Un experimento". En El psicoanálisis y la crianza del niño. Barcelona: Paidós, 1980, 79-128.

(28) Freud, A. "Las necesidades de la educación temprana". En El psicoanálisis y la crianza del niño. Barcelona: Paidós, 1980, 35-45.

(29) Freud, A. "Los hábitos alimentarios. Sus perturbaciones". En El psicoanálisis y la crianza del niño. Barcelona: Paidós, 1980, 59-74.

(30) Freud, A. "Los hábitos alimentarios. Su establecimiento". En El psicoanálisis y la crianza del niño. Barcelona: Paidós, 1980, 47-57.

(31) Freud, A. "Perturbaciones en el dormir". En El psicoanálisis y la crianza del niño. Barcelona: Paidós, 1980, 75-78.

(32) Freud, A. "La pérdida de objetos. Perder y perderse". En El psicoanálisis y la crianza del niño. Barcelona: Paidós, 1980, 147-157.

(33) Freud, A. "Indicaciones para el análisis". En El psicoanálisis infantil y la clínica. Buenos Aires: Paidós, 1977, 71-96.

(34) Freud, A. "Contraindicaciones para el análisis". En El psicoanálisis infantil y la clínica. Buenos Aires: Paidós, 1977, 97-106.

(35) Sandler. J., Kennedy, H. y Tyson, R. Conversaciones con Anna Freud. La técnica en psicoanálisis de niños. Buenos Aires: Gedisa, 1983.

(36) Appignanesi, L. y Forrester, J. Las mujeres de Freud. Buenos Aires: Planeta, 1994.

(37) Sandler, J. L'analyse de défense. Entretiens avec Anna Freud. Paris: PUF, 1989

(38) Freud, A. El desarrollo del niño. Observaciones. En Psicoanálisis del desarrollo del niño y del adolescente. Barcelona: Paidós, 1992, 11-26.

(39) Freud, A. "Contribuciones del psicoanálisis a la psicología genética". En El psicoanálisis infantil y la clínica. Buenos Aires: Paidós, 1977, 43-68.

(40) Sayers, J. Les mères de la psychanalyse. Paris: PUF, 1995.

(41) Freud, A. "Enfermedad somática y vida psíquica". En El psicoanálisis y la crianza del niño. Barcelona: Paidós, 1980, 131-145.

(42) Freud, A. "La visita al niño hospitalizado". En El psicoanálisis y la crianza del niño. Barcelona: Paidós, 1980, 171-171. 
(43) Freud, A. "El conocimiento psicoanalítico y la crianza". En El psicoanálisis y la crianza del niño. Barcelona: Paidós, 1980, 11-20.

(44) Freud, A. "La observación directa del niño. Su aportación al psicoanálisis". En El psicoanálisis infantil y la clínica. Buenos Aires: Paidós, 1977, 30.34.

(45) Freud, A. "Evolución de la psicología psicoanalítica del niño". En El psicoanálisis infantil y la clínica. Buenos Aires: Paidós, 1977, 35-42.

(46) Freud, A. "Breve historia del análisis de niños". En El psicoanálisis infantil y la clínica. Buenos Aires: Paidós, 1977, 11-18.

(47) Freud, A. "La observación de niños y la predicción del desarrollo". En Psicoanálisis del desarrollo del niño y del adolescente. Barcelona: Paidós, 1992, 41-64.

(48) Freud, A. "La terminación del análisis". En El psicoanálisis infantil y la clínica. Buenos Aires: Paidós, 1977, 107-120.

(49) Freud, A. "La clínica de orientación infantil como centro de prevención y esclarecimiento". En El psicoanálisis infantil y la clínica. Buenos Aires: Paidós, 1977, 130-142.

(50) Freud, A. "La adolescencia". En Psicoanálisis del desarrollo del niño y del adolescente. Barcelona: Paidós, 1992, 165-185.

(51) Freud, A. "Respuestas para pediatras". En El psicoanálisis y la crianza del niño. Barcelona: Paidós, 1980, 191-208.

(52) Freud, A. "El trauma psíquico". En Neurosis y sintomatología en la infancia. Barcelona: Paidós, 1984, 11-25.

(53) Freud, A. "El niño en el hospital". En El psicoanálisis y la crianza del niño. Barcelona: Paidós, 1980, 159-170.

(54) Freud, A. "El cuidado de los niños en instituciones y en hogares sustitutos". En El psicoanálisis y la crianza del niño. Barcelona: Paidós, 1980, 177-189.

(55) Freud, A. "Dificultades en el camino del psicoanálisis". En Pasado y presente del psicoanálisis. México: Siglo XXI, 1972, 13-57.

(56) Freud, A. "Los conocimientos psicoanalíticos aplicados a la educación infantil". En Pasado y presente del psicoanálisis. México: Siglo XXI, 1972, 61-79.

(57) Freud, A. "La sintomatología de la infancia". En Neurosis y sintomatología de la infancia. Barcelona: Paidós, 1984, 26-48.

(58) Freud, S. The Essentials of Psycho-Analysis. London: Penguin Books, 1991.

(59) Freud, A. "Introduction (A Study Guide to Freud's Writing)". En The Essentials of Psycho-Analysis. London: Penguin Books, 1991.

(60) Freud, A. The Writings of Anna Freud. Vols. I-VIII. New York: International Universities Press. 1980

*Psicóloga

Departamento de Psicología Evolutiva y de la Educación

Universidad de Sevilla

Correspondencia: Pza. Dr. González Gramage, 2-11 B. 41005 Sevilla

Fecha de recepción: 23-11-01 